\title{
Formulasi Prinsip Bagi Hasil Perjanjian Sewa Menyewa Tanah Dalam Rangka Pemberian Hgb/Hak Pakai Di Atas HM
}

\author{
Hasmonel \\ hasmonel@ecampus.ut.ac.id \\ FHISIP - UT \\ Lego Karjoko (Fakultas Hukum UNS)
}

\begin{abstract}
Abstrak
Pengaturan hubungan hukum antara pemegang HGB/Hak Pakai dan pemegang HM ini diarahkan untuk terwujudnya usaha agraria yang berkeadilan dan mensejahterakan rakyat, sehingga dapat memutus rantai kemiskinan atau mencegah struktur agraria yang tidak adil. Model hubungan hukum pertanahan ini diharapkan dapat menyelesaikan konflik pertanahan yang sebagai akibat ketimpangan struktur agraria. Target utama memperoleh masukan penyempurnaan model formulasi prinsip bagi hasil dalam perjanjian sewa menyewa tanah dalam rangka pemberian $\mathrm{HGB} / \mathrm{Hak}$ Pakai di atas HM. Metode yang digunakan yaitu kualitatif dengan interaksi simbolik, yaitu merekonstruksi penyesuaian tindakan dari tiga subyek hubungan hukum yaitu pemegang HGB/Hak Pakai, pemegang HM dan Badan Pertanahan Nasional (BPN). Untuk mencapai solusi integrative mengenai suatu tatanan yang mampu menyelesaikan masalah pertanahan secara adil digunakan bridging dengan kata lain peneliti memposisikan diri sebagai jembatan atau fasilitator bagi ketiga subyek hubungan hukum. Di tengah ketiga subyek ini, pemakalah merupakan subyek keempat yang berfungsi sebagai jembatan/fasilitator konsensus Dapat disimpulkan bahwa perjanjian pemegang HM dengan pemenang HGB sebagai penyewa diperlukan campur tangan kebijakan pemerintah, yang berperan mengharmonisasikan sekaligus melindungi kepentingan pemegang Hak Milik dan penyewa tanah dalam bentuk formulasi prinsip bagi hasil dalam pemberian HGB/Hak Pakai di atas Hak Milik yang diawali dengan perjanjian sewa menyewa tanah. Prinsip bagi hasil harus mempertimbangkan faktor dominan yang mempengaruhi besaran sewa tanah yang berkeadilan dan berkelanjutan antara lain lokasi tanah, nilai
\end{abstract}


jual objek pajak, harga pasar tanah, biaya operasional, bangunan yang ada dengan formulasi 3 (tiga) tahap sebagai berikut

a. Formulasi tanah mentah/lahan kosong, tanpa sarpras, fasilitas, infrastruktur dan lain-lain :

Tahap I dibayarkan pada awal perjanjian

(NJOP x luas lahan) - 5\%

Tahap II dibayarkan setelah selesai 1/3 waktu perjanjian

NJOP x luas lahan

$1 / 3 \times$ sisa waktu perjanjian

Tahap III dibayarkan setelah selesai 2/3 waktu perjanjian

\section{NJOP x luas lahan \\ $1 / 3 \times$ sisa waktu perjanjian}

b. Formulasi tanah matang yang sudah memiliki bangunan (sarpras, fasilitas, infrastruktur dan lain-lain :

Tahap I dibayarkan pada awal perjanjian

$$
\frac{(\mathrm{NJOP}+\text { harga pasar) } \mathrm{x} \text { luas lahan }}{2}+\frac{\text { Nilai bangunan }}{\text { Usia bangunan }}
$$

Tahap II dibayarkan setelah selesai 1/3 perjanjian

NJOP x luas lahan + Nilai bangunan baru dan sarpras

$1 / 3 \times$ sisa waktu perjanjian Usia bangunan existing

Tahap III dibayarkan setelah selesai 2/3 waktu perjanjian

NJOP x luas lahan + Nilai bangunan baru dan sarpras

$1 / 3 \times$ sisa waktu perjanjian Usia bangunan existing 


\section{Pendahuluan}

Pada tataran filosofis, hukum tanah nasional tidak membenarkan tanah dijadikan sebagai instrument mencari keuntungan (tanah bukan sebagai komoditas). Pada tataran empiris di era liberalisasi, salah satu diantaranya melalui ketentuan Masyarakat Ekonomi Asean (MEA), melalui investasi berbasis tanah (sektor pertanian, kehutanan, dan pariwisata) fungsi tanah telah bergeser menjadi barang komoditas. Menurut Taylor dan Bending (2009), tekanan komersial akan terus terjadi melalui investasi asing (foreign direct investment), sehingga diperlukan pengaturan untuk mencegah dan meminimalkan kemungkinan adanya rente, laba tanpa kerja dari proses produksi.

Industri pariwisata yang menjadi daya tarik utama Propinsi Bali, membutuhkan lahan tanah sebagai salah satu penunjangnya. Untuk memenuhi kebutuhan akan tersedianya lahan penunjang sarana dan prasarana pariwisata dan menjaga kelestarian tanah-tanah yang ada di Bali maka tanah-tanah yang ada di Bali banyak yang disewakan dalam jangka waktu yang sangat panjang. Dalam Peraturan Pemerintah Nomor 40 Tahun 1996 tentang Hak Guna Usaha, HGB, dan Hak Pakai atas Tanah, dikenal Pemberian HGB (HGB) di atas HM (HM) atas tanah. Pemberian HGB di atas HM diartikan, para penduduk asli Bali yang mempunyai tanah-tanah HM, dapat bekerja sama dengan pihak lain (investor) melalui suatu perjanjian permulaan pemberian HGB di atas HM atau sewa-menyewa yang memuat kesepakatan kedua belah pihak bahwa di atas tanah HM yang diperjanjikan tersebut akan dibebani/diberikan HGB.

Asas fungsi sosial hak atas tanah (Pasal 6 UUPA) memberi amanah agar pengaturan hubungan hukum mengenai pemanfaatan tanah harus memberi 
keuntungan yang seimbang bagi investor sebagai pemegang HGB dan penduduk Bali sebagai pemegang HM. Menurut Deininger dkk, (2010), untuk memastikan sewa menyewa tanah tersebut menguntungkan bagi pihak investor maupun penduduk Bali diperlukan Code of Conduct For Responsible Invesment (kode etik untuk investasi yang bertanggung jawab), berupa penghormatan hak atas tanah dan sumber daya, memastikan ketahanan pangan, transparansi, good governance dan lingkungan yang kondusif, konsultasi dan partisipasi, investasi pertanian yang bertanggung jawab, keberlanjutan kehidupan sosial dan ekologis.

Tulisan ini dimaksudkan untuk memberikan model formulasi prinsip bagi hasil perjanjian sewa menyewa tanah dalam rangka pemberian $\mathrm{HGB} / \mathrm{Hak}$ Pakai di atas HM yang berkeadilan berkelanjutan

\section{Kerangka Teori}

Pasal 33 ayat (3) UUD 1945 Jo Pasal 2 ayat (2) UUPA, secara konstitusional menjadi landasan berlakunya penguasaan oleh negara atas bumi, air, dan kekayaan alam yang terkandung didalamnya. Pasal ini sering disebut sebagai dasar yang mengatur tentang hak menguasai atau penguasaan oleh negara, tetapi tidak bisa berdiri sendiri melainkan memiliki keterkaitan dengan kesejahteraan rakyat.

Fungsi pengaturan lewat ketentuan yang dibuat oleh legislatif dan regulasi oleh eksekutif, fungsi pengurusan dilakukan oleh eksekutif dengan cara mendayagunakan penguasaannya atas sumber-sumber alam untuk sebesar-besarnya kemakmuran rakyat, dan fungsi pengawasan adalah mengawasi dan mengendalikan agar pelaksanannya benar untuk sebesarbesarnya kemakmuran rakyat (Ahmad Sodiki, 2013: 253-254). Pada tataran 
empiris terdapat kebutuhan untuk menyeimbangkan kebebasan pemegang HM dengan investor. Negara dapat membuat undang-undang untuk melindungi dan melindungi dan melekatkan kewajiban-kewajiban tertentu pada perjanjian pemanfaatan lahan. Kebebasan berkontrak masih dianggap sebagai aspek yang esensial dari kebebasan individu, tetapi tidak lagi memiliki nilai absolute (W Friedmann, 1960 : 47-48).

\section{Fungsi Sosial Hak atas tanah dan Teori Keadilan}

Adanya fungsi sosial hak atas tanah berarti bahwa tanah juga bukan komoditas perdagangan, biarpun dimungkinkan tanah yang dipunyai dijual jika ada keperluan, oleh karena itu tanah tidak boleh dijadikan obyek investasi semata-mata (Boedi Harsono, 2003: 304). Agus Surono dalam tulisannya mengenai fungsi sosial tanah menyatakan bahwa pelaksanaan konsep fungsi sosial hak atas tanah tidak lepas dengan adanya pelaksanaan konsep negara kesejahteraan (welfare state). Menurut konsep Negara kesejahteraan, tujuan negara adalah untuk kesejahteraan umum. Negara dipandang hanya alat untuk mencapai tujuan bersama kemakmuran dan keadilan sosial bagi seluruh rakyat negara tersebut (Agus Surono, 2013:6).

\section{Metode Penelitian}

Penelitian ini menggunakan metode penelitian kualitatif dengan interaksi simbolik sebagai strategi penelitian. Untuk mencapai solusi integrative mengenai dalam menyelesaikan masalah pertanahan secara adil digunakan bridging. Di tengah ketiga subyek ini, peneliti merupakan subyek keempat yang berfungsi sebagai jembatan/fasilitator consensus. 


\section{Proses Pemberian HGB di atas HM}

Pasal 24 PP No 40 Tahun 1996, pemberian HGB di atas tanah HM terjadi pada saat dibuatnya akta pemberian HGB di atas tanah HM oleh PPAT. Pendaftaran yang dilakukan di kantor pertanahan adalah hanya untuk mengikat pihak ketiga, dan menjadi sahnya pemberian tersebut. Peraturan Perundang-undangan ini sebetulnya mengamanatkan bahwa untuk tata cara pemberian dan pendaftaran pemberian HGB di atas tanah HM akan diatur lebih lanjut dengan Keputusan Presiden. Namun sampai saat ini aturan tersebut belum juga ada sehingga dalam pelaksanaanya sering menimbulkan permasalahan.

Hasil wawancara dengan Notaris-PPAT Paramita Rukmi (tanggal 3 Agustus 2015) yang kemudian diperkuat lagi oleh Notaris-PPAT Lumasia (wawancara 15 Agustus 2016), ada empat akta menjadi dasar hukum dari hubungan antara pemegang HGB dan HM Akta Sewa Menyewa, Akta Kuasa dan Akta Pemberian HGB di atas tanah HM

Besarnya uang sewa/imbalan/ganti kerugian selama 30 tahun dapat dilihat dalam tabel di bawah ini.

Tabel HGB di atas HM Kabupaten Badung Tahun 2015

\begin{tabular}{|c|l|c|l|r|}
\hline No & $\begin{array}{c}\text { Pemegang } \\
\text { HGB }\end{array}$ & $\begin{array}{c}\text { Luas } \\
(\mathrm{m} 2)\end{array}$ & \multicolumn{1}{|c|}{ Peruntukan } & Uang Sewa \\
\hline 1 & PT. AB & 1.350 & Akomodasi wisata & $1.000 .000 .000,-$ \\
\hline 2 & PT. DII & 1.975 & Akomodasi wisata & $1.000 .000 .000,-$ \\
\hline 3 & PT. DPS & 2.090 & Akomodasi wisata & $627.000 .000,-$ \\
\hline 4 & PT. WPK & 2.362 & Akomodasi wisata & $150.400 .000,-$ \\
\hline 5 & PT. WPK & 2.362 & Akomodasi wisata & $151.168 .000,-$ \\
\hline 6 & PT. SSW & 280 & Akomodasi wisata & $563.640 .00,_{-}-$ \\
\hline 7 & PT. SSW & 1.267 & Akomodasi wisata & $2.616 .900 .000,-$ \\
\hline 8 & PT. BJP & 3.900 & Akomodasi wisata & $9.016 .200 .000,-$ \\
\hline 9 & PT. BJI & 11.630 & Akomodasi wisata & $38.280 .000 .000,-$ \\
\hline 10 & PT. SBP & 3.515 & Akomodasi wisata & $1.053 .000 .000,-$ \\
\hline
\end{tabular}




\begin{tabular}{|l|l|c|l|r|}
\hline 11 & PT. SVB & 10.000 & Akomodasi wisata & $8.550 .000 .000,-$ \\
\hline 12 & PT. DPS & 4.910 & Akomodasi wisata & $1.473 .000 .000,-$ \\
\hline 13 & DPG & 4.951 & Akomodasi wisata & $11.844 .000 .000,-$ \\
\hline
\end{tabular}

Sumber : Kantor Pertanahan Kabupaten Badung

Uang Sewa dalam Pemberian HGB di atas HM

Kabupaten Badung dan Gianyar Hasil Wawancara

\begin{tabular}{|c|l|c|c|r|c|}
\hline No & $\begin{array}{c}\text { Pemegang } \\
\text { HGB }\end{array}$ & $\begin{array}{c}\text { Jangka } \\
\text { Waktu }\end{array}$ & $\begin{array}{r}\text { Tahun perjj } \\
\text { sewa }\end{array}$ & $\begin{array}{c}\text { Luas } \\
(\mathrm{m} 2)\end{array}$ & Uang Sewa \\
\hline 1 & PT. DII & 30 Thn & 2002 & 1.975 & $1.000 .000 .000,-$ \\
\hline 2 & PT. JBV & $25 T h n$ & 2007 & 1.550 & $2.000 .000 .000,-$ \\
\hline 3 & PT, DVT & 25 Thn & 2009 & 2000 & $2.700 .000 .000,-$ \\
\hline 4 & IKA & 40 Thn & 2012 & 10.670 & $4.040 .000 .000,-$ \\
\hline
\end{tabular}

Sumber : Hasil Wawancara Tahun 2016

Hasil analisis terhadap isi dokumen perjanjian sewa menyewa tanah, perjanjian pendahuluan, dan akta pemberian HGB di atas HM dan wawancara dengan Notaris-PPAT yang dilakukan tahun 2015 dapat diketahui bahwa terdapat indikasi ketidakadilan bagi pemegang Hak Milik tertentu (walau tidak dialami semua pemegang Hak Milik) dalam hubungan hukum dengan penyewa tanah sebagai pemegang Hak Guna Bangunan. Di lokasi tertentu pada tahun ke 10 - 12 terdapat investor selaku pemegang HGB sudah break even point (BEP/balik modal) dan menikmati keuntungan yang besar dalam 18 - 20 tahun sisa waktu pemanfaatan tanah HGB tersebut. Beberapa manajemen penyedia jasa akomodasi/hotel di tahun 2016, mengindikasikan tidak semua mengalami kesuksesan karena over penawaran.

Narasumber lain yang objek tanah sewanya berlokasi di daerah Pecatu mengungkapkan bahwa memang bisnis hotel cenderung lebih banyak diminati oleh investor bukan hanya di daerah tujuan yang sudah dikenal objek wisatanya tetapi juga di daerah-daerah yang baru akan dikembangkan. 
Hal ini dikarenakan bisnis hotel lebih aman, sifatnya jangka panjang dan bisa bertahan lama. Pemasukan utama bisnis hotel/villa/cottage berasal dari pelanggan yang menginap, lokakarya dan event-event yang diadakan oleh vendor, baik instansi swasta maupun pemerintah, seminar dan beberapa tahun terakhir pesta pernikahan pasangan luar Bali semakin lama semakin diminati. Keuntungan bisnis hotel akan sangat terasa bila owner memiliki sendiri lahannya dengan alas Hak Milik, keuntungan itu akan berlipat ganda disebabkan kenaikan harga jual lahan, dibanding pada saat pertama membeli lahan tanah tersebut. Khusus untuk Bali, di samping ada yang berdiri di atas lahan milik sendiri, faktanya cukup banyak investor mendirikan hotel dengan alas Hak Guna Bangunan di Atas Hak Milik dikarenakan investor tidak memenuhi persyaratan memiliki tanah dengan alas Hak Milik. Dengan tidak memenuhi persyaratan menjadi pemegang Hak Milik maka investor mendirikan hotel di atas tanah Hak Milik orang lain dengan didahului oleh perjanjian sewa-menyewa tanah dalam jangka panjang-menengah. Berdasarkan perjanjian sewa menyewa tanah itu investor mengajukan permohonan akta pemberian Hak Guna Bangunan. Berbeda kondisinya bila pengusaha hotel tersebut lahannya milik sendiri, dimana biaya lahan cukup dikeluarkan diawal investasi, pengusaha hotel dengan Hak Guna Bangunan di atas Hak Milik akan mengeluarkan biaya lahan (sewa) berkali-kali dengan cara perpanjangan sewa. Pengusaha hotel dengan cara sewa lahan ini tidak menikmati keuntungan dari peningkatan harga lahan melainkan justru menanggung beban peningkatan sewa lahan sebagai konsekuensi logis pengaruh peningkatan harga lahan, peningkatan kualitas lingkungan, naiknya NJOP dan semakin padatnya lingkungan sekitar. Bahkan di daerah-daerah strategis di kota Denpasar maupun Kabupaten Badung harga sewa lahanpun 
sudah sangat tinggi dibandingkan dengan daerah lain, nilai sewa lahan ada yang hampir sebanding dengan nilai jual putus lahan yang berstatus Hak Milik.

Berdasarkan alasan-alasan tersebut di atas maka dapat dipahami bahwa pengusaha hotel dengan pemberian Hak Guna Bangunan di Atas Hak milik baru akan mencapai BEP setelah tahun 15 tahun hotel beroperasi, dan bahkan ada yang di atas 18 tahun setelah hotel beroperasi. Namun belum pernah mendengar ada pengusaha yang mengalami BEP menjelang berakhirnya $\mathrm{HGB} /$ Hak Pakai atau tidak mengalami BEP sampai berakhirnya perjanjian sewa-menyewa tanah. Kesulitan, hambatan dan tantangan yang dialami oleh pengusaha hotel ini tidak pernah dirasakan atau dialami oleh pemegang Hak Milik.

Wawancara dengan pemegang Hak Milik yang tanahnya disewa untuk 30 tahun dan sekarang di bangun hotel (HGB) 13 tahun yang lalu, beranggapan bahwa saat ini kemungkinan besar penyewa tanah sudah mengalami BEP atau paling tidak modal kembali sudah di atas $90 \%$, sehingga sisa 16-17 tahun ke depan itu sudah murni keuntungan penyewa, sementara pemilik hanya bisa menunggu sampai berakhirnya perjanjian sewa dan nilai bangunan hotel sudah sangat rendah karena penyusutan (usia bangunan sudah sama dengan lama perjanjian sewa tanah yaitu 30 tahun).

Adapun perhitungan yang diberikan oleh pemegang Hak Milik sebagai berikut

1. Modal membangun hotel termasuk sewa tanah sekitar Rp50.000.000.000,-

2. Jumlah kamar yang dihuni per Hari/malam $=40$ kamar

3. Biaya per kamar rata-rata Rp400.000,- dikurangi biaya operasional dan gaji karyawan Rp100.000,-= Rp300.000,-

4. Hitungan BEP 50.000.000.000/(40 $\times$ Rp300.000 $)=4.167$ hari $/ 360=11.5$ tahun ditambah 2 tahun pembangunan hotel $=13$ tahun 
Pengusaha/manajemen hotel, merespons secara diplomatis "mungkin pemegang Hak Milik menghitung biaya operasional itu hanya pengeluaran gaji karyawan, akomodasi, langganan daya dan jasa saja tetapi kalkulasi dan analisis BEP tidak sesederhana itu, apalagi di Indonesia, banyak sekali biaya-biaya yang tidak bisa dipredeksi diawal, karena kenaikan hargaharga juga dipengaruhi oleh menurunnya nilai/kurs rupiah. Komponen lain, yang mempengaruhi biaya operasional seperti pajak hotel, pajak pembangunan, maintenance, perlengkapan kamar dan asesoris hotel, penggantian barang rusak atau hilang, termasuk fluktuasi tingkat hunian dan biaya promosi serta kenaikan upah minimum regional, kesemuanya menjadi variabel biaya operasional. Semakin tinggi sewa kamar biasanya akan semakin tinggi layanan yang harus diberikan dan hal itu berdampak juga kepada biaya operasional. Biaya operasional untuk tingkat hunian dibawah $60 \%$ tidak pernah kurang dari 35\% dari rata-rata harga sewa kamar. Semakin kecil persentase hunian maka akan semakin besar persentase biaya operasional yang dikeluarkan, semakin besar tingkat hunian maka persentase biaya operasional akan semakin kecil. Untuk tingkat hunian di atas $60 \%$, biaya operasional akan lebih kecil dari 35\% dari rata-rata harga sewa kamar. Dengan mengambil contoh yang diprediksi pemegang Hak Milik di atas, dengan diasumsikan rata-rata $32.5 \%$ biaya yang dikeluarkan dari sewa kamar, maka sewa bersih perkamar adalah 67.5\% x Rp400.000,- =Rp250.000,- x 40 kamar, jadi penghasilan perhari $/$ malam $=$ Rp10.000.000,-. Maka di atas kertas BEP diperkirakan terjadi pada hari ke 5.000 atau setelah 13 tahun 10 bulan hotel beroperasi atau kira-kira 16 tahun sejak kontrak sewa menyewa ditanda tangani. Asumsi di atas berlaku untuk tingkat hunian kamar di atas 50\% tetapi di bawah 60\%. Dengan BEP yang dicapai setelah 16 tahun kontrak sewa 
menyewa, berarti masih tersisa lebih kurang 14 tahun, manajemen harus tetap berupaya secara serius dan dengan berbagai kiat supaya memiliki/terkumpul dana/modal agar dapat memperpanjang kontrak baru (tahap kedua) atau mencari lahan lain yang dianggap lebih menguntungkan. Kontrak sewa tanah tahap kedua justru merupakan keuntungan pemegang Hak Milik, karena harga sewa akan jauh lebih besar di bandingkan dengan harga sewa pada saat kontrak pertama dan berhubung bangunan sudah dianggap milik pemegang Hak Milik tanah maka beban penyewa tanah (pemegang HGB) secara tidak langsung bertambah.

Disamping kecil risikonya beberapa keuntungan lain pemegang Hak Milik:

a. Sewa tanah di daerah strategis, pada kisaran $60-80 \%$ dari harga pasaran tanah (luas tanah 3900M2 disewa selama 30 tahun sebesar Rp9.016.200.000 atau rata2 Rp 2.300.000/meter), di mana pada waktu itu pasaran harga jual tanah di wilayah tersebut berkisar antara Rp3.250.000,- s/d Rp4.000.000,- atau Rp.300 - Rp.400 juta/are bahkan ada yang lebih dari $80 \%$ luas tanah $11.630 \mathrm{M} 2$ disewa selama 30 tahun sebesar Rp38.280.000.000 atau rata2 Rp3.300.000/meter, di mana pada waktu itu pasaran harga jual tanah di wilayah tersebut berkisar antara Rp4.000.000 - Rp5.000.000,- atau Rp.400 - Rp.500 juta/are.

b. Harga sewa setinggi itu bisa terjadi disebabkan banyak investor asing hanya memenuhi persyaratan menguasai tanah dengan Hak Guna Bangunan dan memiliki nilai uang/kurs jauh lebih tinggi dari rupiah $(\$ 1=$ Rp13.000) tetapi hal jarang terjadi bila disewa oleh investor yang memiliki persyaratan sebagai pemegang Hak Milik atas Tanah karena investor yang memiliki persyaratan memiliki tanah dengan Hak Milik, cenderung tidak menyewa tetapi membeli tanah tersebut.

c. Pemegang Hak Milik sangat dimungkinkan memanfaatkan hasil sewa tanah untuk usaha/bisnis yang berpenghasilan misalnya usaha transportasi/travel biro, pertokoan, restoran, dan usaha-usaha pendukung pariwisata lainnya.

d. Pemegang Hak Milik dapat memanfaatkan hasil sewa tanah untuk membeli lahan lain yang berpotensi menjadi daerah wisata baru. 
e. Nilai dan harga tanah yang disewakan semakin lama semakin tinggi, jauh meningkat dibanding pada saat baru disewakan dan kenaikan harga akan dinikmati di akhir perjanjian sewa.

f. Pemegang Hak Milik dan anggota keluarga mendapatkan sejenis "privilege" atau keistimewaan untuk bekerja pada penyewa lahan sesuai keahlian yang dimiliki sambil secara tidak langsung mengawasi lahan tersebut.

g. Sewa tahap kedua akan disesuaikan dengan kondisi pada saat menjelang berakhirnya perjanjian sewa-menyewa.

h. Bangunan yang didirikan oleh penyewa lahan biasanya sudah masuk dalam perhitungan kenaikan sewa lahan tahap kedua.

Keuntungan-keuntungan tersebut seharusnya menjadi pertimbangan pemegang Hak Milik agar tidak terlalu banyak menuntut dan apriori terhadap keuntungan pengusaha hotel. Investor yang menanamkan modalnya diusaha perhotelan pada dasarnya menghidupkan roda perekonomian daerah pariwisata, dan bila terlalu banyak tuntutan bukan tidak mungkin mengakibatkan penarikan modal dan menurunnya minat pengusaha hotel maka pemilik tanah dan masyarakat sekitar jugalah yang pertama-tama akan merasakan dampaknya.

Hasil wawancara sewa tanah dengan berbagai pihak dapat disimulasikan melalui bagan dan tabel seperti di bawah ini 

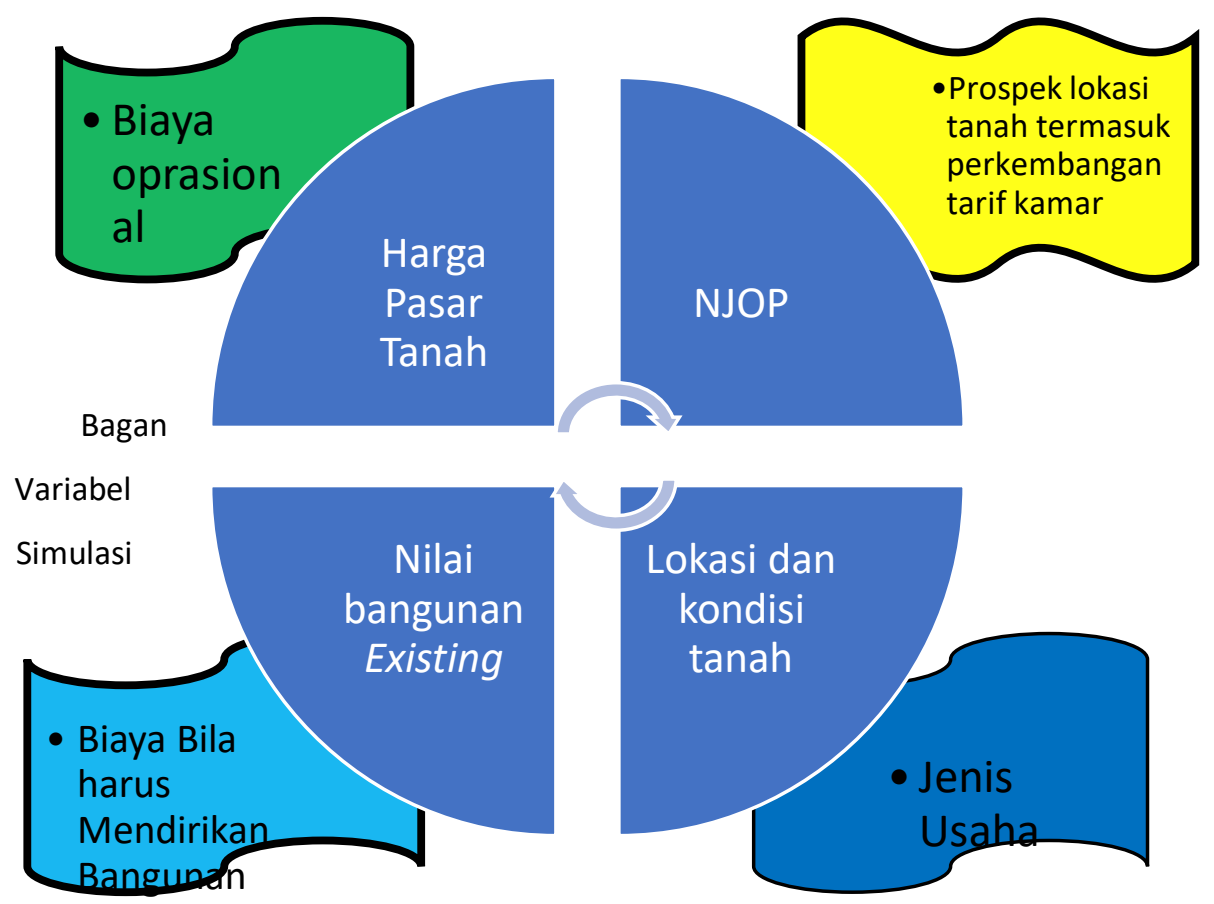

Formulasi Prinsip Bagi Hasil

Simulasi Perhitungan Sewa Tanah

\begin{tabular}{|c|c|c|c|c|}
\hline No & $\begin{array}{c}\text { Komponen/ } \\
\text { Variabel }\end{array}$ & $\begin{array}{c}\text { Perjanjian Sewa } \\
\text { tahap I }\end{array}$ & $\begin{array}{c}\text { Perjanjian Sewa } \\
\text { tahap II }\end{array}$ & $\begin{array}{l}\text { Keterangan/ } \\
\% \text { kenaikan }\end{array}$ \\
\hline 1 & Luas Tanah & \multicolumn{2}{|c|}{10.670} & \\
\hline 2 & Status Tanah & Hak Adat & Hak Milik & $\begin{array}{l}\text { Peningkatan } \\
\text { status pemilikan }\end{array}$ \\
\hline 3 & Lokasi tanah & \multicolumn{2}{|c|}{$\begin{array}{c}\text { Desa Adat Pejeng Kawan Tampak } \\
\text { Siring Gianyar, Bali }\end{array}$} & pinggir desa \\
\hline 4 & Kondisi tanah & Ladang & tanah matang & pengembangan \\
\hline 5 & NJOP & $400.000,-/ M$ & $2.000 .000 / \mathrm{M}$ & $500 \%$ \\
\hline 6 & Harga Pasar & $750.000 / \mathrm{M}$ & $5.250 .000 / \mathrm{M}$ & $700 \%$ \\
\hline 7 & $\begin{array}{l}\text { Nilai Bangunan, } \\
\text { sarana/ } \\
\text { prasarana }\end{array}$ & 0 & $\begin{array}{l}120.000 .000 .00 \\
0\end{array}$ & $\begin{array}{l}\text { Prakiraan nilai } \\
\text { bangunan }\end{array}$ \\
\hline
\end{tabular}




\begin{tabular}{|c|l|c|c|c|}
\hline 8 & $\begin{array}{l}\text { Fasilitas/ } \\
\text { Infrastruktur }\end{array}$ & Tidak ada & $\begin{array}{r}\text { Jalan } \\
\text { lingkung- an, } \\
\text { listrik, air }\end{array}$ & pengembangan \\
\hline 9 & $\begin{array}{l}\text { Prospek lokasi } \\
\text { tanah }\end{array}$ & $\begin{array}{r}\text { Perkembangan tarif, daerah } \\
\text { favorit atau bukan }\end{array}$ & Tidak diketahui \\
\hline
\end{tabular}

Analisis terhadap hasil wawancara dan data besaran sewa tanah, ternyata faktor dominan yang sangat mempengaruhi besar kecil sewa tanah yaitu lokasi tanah yang tercermin pada kondisi tanah, NJOP, harga pasar tanah dan biaya operasional. Sedangkan nilai bangunan tercermin pada unsur sarana/prasarana, fasilitas dan infrastruktur yang ada di sekitar tanah.

\section{Bagan Faktor Dominan}

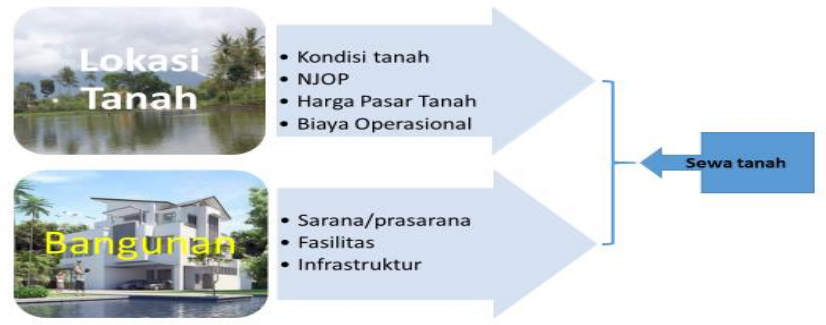

\section{Yang Mempengaruhi Sewa/Harga Tanah}

\section{A. Penutup}

1. Dalam melindungi kepentingan warga negaranya, Indonesia terkesan menganut konsep peran negara minimal karena isi perjanjian sewa menyewa tanah diserahkan sepenuhnya kepada para pihak yang akan melakukan perjanjian.

2. Prinsip bagi hasil harus mempertimbangkan faktor dominan yang mempengaruhi besaran sewa tanah yang berkeadilan dan berkelanjutan antara lain lokasi tanah, nilai jual objek pajak, harga 
pasar tanah, biaya operasional, bangunan yang ada dengan formulasi 3 (tiga) tahap sebagai berikut

a. Formulasi tanah mentah/lahan kosong, baru pertama kali dikembangkan belum memiliki sarpras, fasilitas, infrastruktur dan lain-lain :

Tahap I dibayarkan pada awal perjanjian

(NJOPx luas lahan) $-5 \%$

Tahap II dibayarkan setelah selesai 1/3 waktu perjanjian
NJOP x luas lahan
$1 / 3 \times$ sisa waktu perianiian

Tahap III dibayarkan setelah selesai 2/3 waktu perjanjian

$$
\frac{\text { NJOP x luas lahan }}{1 / 3} \times
$$

b. Formulasi tanah matang yang sudah memiliki bangunan (sarpras, fasilitas, infrastruktur dan lain-lain :

Tahap I dibayarkan pada awal perjanjian

$$
\frac{(\mathrm{NJOP}+\text { harga pasar }) \times \text { luas lahan }}{2}+\frac{\text { Nilai bangunan }}{\text { Usia bangunan }}
$$

Tahap II dibayarkan setelah selesai $1 / 3$ waktu perjanjian

NJOP x luas lahan + Nilai bangunan baru dan sarpras $1 / 3 x$ sisa waktu perjanjian Usia bangunan existing 
Tahap III dibayarkan setelah selesai 2/3 waktu perjanjian

\section{NJOP x luas lahan + Nilai bangunan baru dan sarpras} $1 / 3 \times$ sisa waktu perjanjian Usia bangunan existing

3. Jaminan (hak privilege) pemegang HGB/Hak Pakai yang menyewa tanah tahap berikutnya diimbangi hak privilege keikutsertaan pemegang Hak Milik dalam manajemen pemegang HGB/Hak Pakai atau kepemilikan saham perusahaan penyewa tanah.

4. Dalam hubungannya dengan pemberian HGB/Hak Pakai di atas HM, tidak ditemukan indikasi pemilik hak-hak atas tanah yang mengabaikan fungsi sosial hak atas tanah.

\section{A. Saran}

1. Seyogyanya segera diterbitkan Peraturan Presiden yang mengatur pemberian HGB atau Hak Pakai di atas Hak Milik. Peraturan Presiden tersebut dapat mewujudkan hubungan hukum pemanfaatan lahan sehingga menjamin sistem berkeadilan yang berkelanjutan.

2. Diperlukan kebijakan Pemerintah, yang berperan mengharmonisasikan sekaligus melindungi kepentingan pemegang Hak Milik dan penyewa tanah dalam bentuk formulasi prinsip bagi hasil dalam pemberian HGB/Hak Pakai di atas Hak Milik yang diawali dengan perjanjian sewa menyewa tanah.

3. Perlu diatur transparansi manajemen (neraca) perusahaan dan keikutsertaan (saham) pemilik tanah dalam perusahaan penyewa tanah. 


\section{DAFTAR PUSTAKA}

A.A Raka Yadnya. 2003. Pembebanan Hak Guna Bangunan Atau Hak Pakai Di atas Hak Milik. Makalah KAKANWIL BPN Propinsi Bali dalam KONFERDA Ikatan Notaris Indonesia (INI) Daerah Bali-Nusa Tenggara Timur.

Achmad Rubaie,2007, Hukum Pengadaan Tanah Untuk Kepentingan Umum, Malang : Bayumedia Publishing.

Agus Surono, 2013, Fungsi Sosial Tanah , Jakarta: Penerbit Fakultas Hukum Universitas Al-Azhar.

Ahmad Sodiki, 2013, Politik Hukum Agraria, Jakarta : Penerbit Konstitusi Press.

Andina Dyah Pujaningrum, 2014, Perlindungan Hukum Bagi Pemegang HGB Di Atas Hak Milik Atas Tanah di Kabupaten Badung. Denpasar : Tesis Program Pascasarjana, Universitas Udayana

Arie Sukanthi Hutagalung, Markus Gunawan, 2008. Kewenangan Pemerintah di Bidang Pertanahan. Jakarta : PT Raja Grafindo Persada.

Aslan Noor. 2006. Konsep Hak Milik Atas Tanah bagi bangsa Indonesia ditinjau dari Ajaran Hak Asasi Manusia. Bandung : Mandar Maju.

Bernard Arief Sidharta, 2009, Penelitian Hukum Normatif : Analisis Penelitian Filosofikal dan Dogmatikal, Dalam Sulistyowati Irianto dan Shidarta (Editor), Metode Penelitian Hukm Konstelasi dan Refleksi, Jakarta, Yayasan Obor Indonesia.

Boedi Harsono, 2003, Hukum Agraria Indonesia Sejarah Pembentukan Undang-Undang Pokok Agraria, Isi Dan Pelaksanaaanya Jilid 1 Hukum Tanah Nasional. Jakarta: Penerbit Djambatan.

Collin Mac Andrews, 1986, Land Policy in Modern Indonesia. Boston: Oelgeshlager, Gunn \& Haim Publishers Inc.

Gunawan Wiradi,1996. Jangan Perlakukan Tanah Sebagai Komoditi. Jurnal Analisis Sosial. Vol 3/Juli.

Hans Kelsen, 1971, General Theory of Law and State. New York : Russel and Russel. Terj. Raisul Muttaqien. 2006. Teori Umum Tentang Hukum dan Negara. Bandung : Nusamedia dan Nuansa.

J. Satrio, 1995, Hukum Perikatan, Perikatan Yang Lahir Dari Perjanjian, Bandung: Citra Aditya Bakti. 
Karen Lebacqz, 1986, Six Theories of Justice, Indianapolis : Augbung Publishing House, Terjemahan Yudi Santoso, Teori-Teori Keadilan, Bandung : Nusa Media.

Kristen A. Carpenter; Sonia K. Katyal; Angela R. Riley. 2009. "In Defense Of Property". Yale Law Journal. 118 Yale L.J. 1022.

M.C.Mirrow, Origins Of The Social Function Of Property In Chile, Fordham Law Review, Vol.80 Issues 32011.

Mariam Darus Badrulzaman, 2001, Kompilasi Hukum Perikatan, Bandung : Citra Aditya Bakti.

Muchtar Wahid. 2008.Memaknai Kepastian Hukum Hak Milik Atas Tanah, Jakarta : Republika.

Peter Mahmud Marzuki, 2008, Penelitian Hukum, Jakarta, Kencana.

Ridwan Khairandy, 2014, Hukum Kontrak Indonesia Dalam Perspektif Perbandingan (Bagian Pertama), Yogyakarta : FH UII Press.

Roy M.Robbins. 1969. "History of Public Land Law Development". The Journal of American History. Vol. 56, No. 2 (Sep., 1969), pp. 360-362.

R. Santoso. 2006. Pengantar Ilmu Hukum. Jakarta : Sinar Grafika

Rusmadi Murad. 2013. Administrasi Pertanahan. Bandung : Mandar Maju.

Salim H.S. 2005. Hukum Kontrak Teori dan Tehnik Penyusunan Kontrak. Mataram: Sinar Grafika.

Sarjita, Kajian Yuridis Penertiban dan Pendayagunaan Tanah Terlantar Serta Pengenaan Jenis dan Tarif PNBP Yang Berlaku Pada BPN Dalam Upaya Pelaksanaan Kewenangan Daerah Di Bidang Pertanahan. Makalah dalam Diskusi Implementasi PP Nomor 11 dan PP Nomor 13 Tahun 2010 di Kabupaten Sleman.

Satjipto Rahardjo. 2000. Ilmu Hukum. Bandung: Citra Aditya Bakti.

Suraya Afiff, 2005, "Tinjauan atas Konsep Tenure Security Dengan Beberapa Rujukan Pada Kasus-Kasus Di Indonesia", dalam Wacana Edisi 20 Tahun VI.

Sutan Remy Sjahdeini, 2009, Kebebasan Berperjanjian dan Perlindungan Yang Seimbang Bagi Para Pihak Dalam Perjanjian Kredit Bank di Indonesia, Jakarta : PT.Pustaka Utama Grafiti. 
Urip Santoso, 2005, Hukum Agraria dan Hak- Hak Atas Tanah, Jakarta, Prenada Media

Urip Santoso, 2015, Perolehan Hak- Hak Atas Tanah, Jakarta, Prenada Media Will Kymlica, 1990, Contemporary Political Philosophy : an Introduction, New York : Oxford University Press Inc, Terjemahan Agus Wahyudi, 2011, Pengantar Filsafat Poloitik Kontemporer Kajian Khusus Teori-Teori Keadilan, Yogyakarta : Pustaka Pelajar.

Winahyu Erwiningsih, Pelaksanaan Pengaturan Hak Menguasai Negara atas Tanah Menurut UUD 1945, Jurnal Hukum (Ius Quia Iustum) Universitas Islam Indonesia Yogyakarta, Edisi Khusus Vol. 16 Oktober 2009. 